\title{
Melancolia sobre fundo azul
}

Paola Poma

Universidade São Paulo

\begin{abstract}
primeira leitura de Fórmulas de uma luz inexplicável (2012), de Nuno Júdice, provoca certa perplexidade devido à riqueza de cores, imagens e movimentos recorrentes na construção dos poemas. Esta espécie de repetição desordenada suscita no leitor o desejo de rastrear as nuances ali originadas com o objetivo de entender a estratégia do livro, visto que o autor o nomeia como Fórmulas, e, portanto, imagina existir qualquer coisa que garanta uma coesão de leitura, ao mesmo tempo abrindo brechas para a impossibilidade de uma definição (luz inexplicável). De saída, o livro já nos coloca numa situação conflituosa, cujo grau de dificuldade esconde-se na repetição de imagens ou como disse Eduardo Prado Coelho: "Quando se escreve em fluxo e se publica em fluxo, o que sucede é equivalente ao que se passa nos poemas épicos ou nos poemas muito longos: um certo número de poemas estão lá para definir o chão de onde vão emergir os grandes e definitivos poemas. O leitor tem de fazer a diferença e ler nesta perspectiva". ${ }^{1}$ Deste prisma, buscando as repetições, este texto ensaia um olhar atento ao drama do homem que subjaz como imagem central nos poemas de Nuno Júdice.
\end{abstract}

${ }^{1}$ COELHO, 2010,p.56. 


\section{Cores, imagens e movimentos}

Em "Uma antítese e duas analogias" a oposição entre o branco e o preto se desdobra nas imagens das gaivotas e corvos e se amplia nas imagens da lua e do céu vinculadas ao inverno europeu. Tal oposição, de certa forma comum como imagem poética, adquire uma nova dimensão no conjunto do livro visto o branco ser, quase sempre, espaço de abertura, "Procuro a terra branca de um outro continente", 2 "futuro branco"; 3 espaço de desejo, "um coração tão branco", " "num desejo branco de suplício"; 5 de preenchimento, "Foi no centro da praça que ouvi a música branca do coreto vazio" "6 "só o branco me entrega o seu vazio, para que dele faça a folha de papel onde nada escrevo". ${ }^{7}$ O branco como qualificativo não garante a totalidade do ser nem o sinal de pureza, mas, tematiza o lugar do candidato - candidus - que deseja a transfiguração de si, da terra ou do papel como matéria para o poema. Parece-me que tudo o que está branco, ou em branco, nos poemas de Nuno Júdice deseja ser contaminado pela vida, pela escrita, pela arte. Mas, o ato de desejar não assegura a sua realização. Em contrapartida, o preto é indício do caos pressentido no "círculo negro dos olhos marcando a insônia", ${ }^{8}$ nos "cinzentos outonais", 9 nas "negras lágrimas" ${ }^{10} \mathrm{e}$

2 JÚDICE, 2012, p. 11.

${ }^{3}$ JÚDICE, 2012, p. 12.

${ }^{4}$ JÚDICE, 2012, p. 76.

${ }^{5}$ JÚDICE, 2012, p. 103.

${ }^{6}$ JÚDICE, 2012, p. 18.

7 JÚDICE, 2012, p. 101.

8 JÚDICE, 2012, p. 57.

9 JÚDICE, 2012, p. 80.

${ }^{10}$ JÚDICE, 2012, p. 82. 
radicalizado na "sensação de que a noite se tornou mais negra"11 e de que "a poeira das catástrofes levanta-se da sua ira, e enegrece o futuro" ${ }^{12}$

Este contraste entre chiaro/oscuro é potencializado pela forte presença das estações do ano, porém um desvio cromático gerado pela presença da cor azul surge para atenuar a força tensiva do branco e do preto e direciona o olhar ora do sujeito lírico, ora do personagem, ora do próprio leitor para um ponto de fuga do caos. O azul é o céu que se abre como horizonte, possibilidade de voo, natureza apaziguada e apaziguante "e aquilo que era a sombra que habita a noite dissipa-se quando o céu se torna azul". ${ }^{13}$

Escrito com uma pequena paleta de cores, este livro também dialoga profundamente com as artes visuais: fotografia, cinema, escultura, pintura e arquitetura. Em diferentes graus, ora mais abstratos ora mais concretos, as imagens, em especial da mulher, transitam por estes universos e mobilizam a atenção do leitor para o registro fotográfico do preto e branco: "Vejo-a numa fotografia a/preto e branco, quando ainda era jovem./Os cabelos a acabar em trança e os olhos tristes/condizendo com a melancolia da boca.", 14 "Neste esboço há aquele segmento/do teu rosto, quase a preto e branco, que sai da sombra/do taxi; mas faltam as mãos (e sem elas o retrato/ não fica completo).", 15 " A tua nudez/tinha um brilho de fotografia a preto e branco, com a pele/recortada contra a parede.". ${ }^{16}$ Diferentemente das

11 JÚDICE, 2012, p. 85.

12 JÚDICE, 2012, p. 83.

13 JÚDICE, 2012, p. 86.

14 JÚDICE, 2012, p. 36.

15 JÚDICE, 2012, p. 43.

16 JÚDICE, 2012, p. 94. 
fotografias coloridas em que o mimetismo do real anula qualquer possibilidade da presença do inacabado, do esboço e da surpresa, nestas imagens fundadas na luz e na sombra, o olhar do sujeito lírico insiste em capturar o inefável: a tristeza e a melancolia de uma mulher; a fragmentação do corpo que indefine o sujeito e a beleza da nudez que não pode ser tocada. O esboço sugerido pelo retrato permite uma abertura para imaginar o traço inacabado de um corpo ou até mesmo a realização de "uma presença que posso sentir, e me fala/como se estivesses comigo, fazendo-me/ouvir a cor da tua voz. E é como se saísses de dentro/desta imagem que é pura forma, instante/que a palavra reduz à sua duração, gesto/imóvel num desvio do olhar/para o poema.." ${ }^{17}$

Positivo e negativo trabalham para criar uma imagem que, rememorada pela subjetividade do sujeito, se descola do papel e ganha nova forma na poesia. Todavia, se neste "Entre fotografia e poema" a invocação de uma memória amorosa permite o deslocamento da imagem da mulher da película para o texto escrito, concedendo-lhe presença e voz, no poema "A divisão do mundo" se dá justamente o contrário, ou seja, aquilo que é possuído pelo sujeito lírico, o corpo da amada, ao ser posto em versos, deixa de pertencer ao poeta e passa a fazer parte da literatura. Perdas duplas e simultâneas: o poeta perde o seu objeto de desejo e a amada perde a si mesma pois já não sabe se é matéria cantada ou corpo amado. Não temos mais a imagem de um corpo que se deita com outro corpo, mas um corpo que se deita no corpo do poema, numa horizontalidade que se expande pela extensão do verso. Imagem de extrema delicadeza que reforça a tensão da "realidade e seu reflexo":

${ }^{17}$ JÚDICE, 2012, p. 43. 
É um tratado que faço entre mim e mim para te dividir, e saber que este corpo que hoje possuo logo deixará de me pertencer quando o deitar no poema, como alguma vénus de rubens ou banhista de renoir, envoltas em véus ou em arbustos, à luz das velas ou do sol. E sinto o que tenho quando te perco, e o teu corpo se imprime para lá dessa linha abstracta que te separa de ti própria, quando em ti se juntam a realidade e o seu reflexo. ${ }^{18}$

Júdice, portanto, toca na problemática central da arte: a questão da representação. Em que medida o que é cantado faz parte da realidade ou é apenas o seu reflexo? Deformação? Invenção? E a realidade? É possível apreendê-la?

As imagens femininas "retratadas" no livro transitam constantemente do papel, para a tela, para as ruas, para o gesso - como se pode verificar nos títulos sugestivos dos poemas: "Outro retrato com natureza-morta"; "Fotografia de Camille Claudel no hospício", "A escultura"; "Modelo ao ar livre", "Retrato de mulher a um canto do atelier"; "Angelus", "Imagem de mulher" - revelando a fragilidade da linha que separa o real e o imaginário. De todo modo o autor compactua com a hesitação que se insinua no olhar da modelo, olhar que se fixa naquele que a pinta e que se projeta para fora da moldura do quadro:
... Será
essa hesitação que me aproxima
dela, e posso ver na sua atitude
uma angústia que vem de não saber
a que mundo pertence, como se
o seu mundo, de facto, não fosse

${ }_{18}^{18}$ JÚDICE, 2012, p. 25. 
um outro a que damos o nome de beleza, ou de perfeição, em suma, esse breve momento que logo o tempo dissipa, e a morte apaga. ${ }^{19}$

Este obstinado apreço em retratar o feminino se propaga para um universo mais familiar. Em "Álbum", o sujeito lírico resgata, narrativamente, a "mesa da infância". Desejando ouvir uma voz que o transfira para o passado, num lugar outro em que seja possível romper com a solidão e com o caos da vida cotidiana, em que a presença dos avós, primos, pais e visitantes inesperados saboreiam amêndoas e figos secos em torno de uma mesa, depara-se com o silêncio e a solidão.
...Mas
ninguém me chama; e a humidade que escorre pelos vidros da casa, na província, onde o aquecimento não chega para os secar, e as mãos precisam de luvas quando se quer sair à rua, e o inverno nos recebe, é como estes minutos que descem pelo vidro da memória e ali deixam impressas as sombras dos que partiram. É então que limpo com um pano esse vidro: e todos surgem, de novo, à sua transparência, no preto e branco das fotografias que se perderam, ou na súbita impressão de uma voz que, não sei de onde, me volta a chamar para a mesa. ${ }^{20}$

A imagem da umidade escorrendo pelos vidros da casa ao ser aproximada da memória ("vidro da memória") revela a fragilidade do homem diante da sua temporalidade. Independente de um desejo de manter a presença das pessoas e das coisas queridas, a umidade, a frieza, o esquecimento devoram pelas bordas aquilo que outrora existiu. A memória,

19 JÚDICE, 2012, p. 54.

20 JÚDICE, 2012, p. 32. 
portanto, contaminada pelo tempo ("inverno"), necessita de um esforço externo a ela ("limpo com um pano esse vidro"), um esforço do sujeito para que as coisas vividas mantenham a sua presença. Essa tentativa de restaurar o passado como presente não resguarda a realidade do objeto retornado, ao contrário, as imagens voltam "à sua transparência", ou seja, transformadas pelo líquido reagente da memória.

"Casa" também retoma esta nostalgia do passado retratando uma vivência comum: "Havia neste sítio um jardim, ou antes, o que nesse / tempo se chamava um quintal, com a videira... Isto era/ antes do inverno, quando os velhos começavam/ a morrer, e os pés descalços das crianças pareciam/ mais descalços ainda..." 21

A experiência do tempo que passa e transforma tudo ao seu redor garantindo às coisas uma movimentação contínua, concentra-se na ideia de finitude do homem, angústia que percorre grande parte dos poemas deste livro. "Interior vazio" alude à mesma situação: "No interior das grandes casas de outrora,/os velhos encostam-se às ombreiras e ouvem/o gotejar do tempo por entre as mãos. (...) Vi cair essas casas, ouvindo o grito mudo/ das mulheres sombrias que as habitaram. Vi/ os seus olhos cravados em mim, para que as puxasse/de novo para a vida, como se eu conhecesse / o caminho de volta.".22

Os títulos - "Álbum", "Casa" e "Interior Vazio" - possuem certa semelhança de sentido que pode ser unificada na palavra proteção: a presença de um espaço interno na sua estrutura garante a probabilidade de cuidar, de resguardar, de proteger fotos, pessoas, objetos e sentimentos. Porém, em oposição a esta

${ }^{21}$ JÚDICE, 2012, p. 33.

22 JÚDICE, 2012, p. 31. 
proteção contida nos nomes, os poemas tematizam a solidão do homem e o seu enfrentamento com a morte. Tomados de concretude, estes substantivos são esvaziados da sua realidade criando uma espécie de oco dentro daquilo que seria um corpo protetor. Como diria Rosa Maria Martelo, Nuno Júdice utiliza uma "estratégia de concreção do que seria abstrato e uma outra de abstração a partir do que seria o concreto" ${ }^{23}$ Se por um lado as imagens femininas revelam, um traço, um perfil, às vezes um movimento (de encontro ou desencontro) flagrado e fixado pelo olhar do poeta/pintor, por outro as imagens que resgatam uma vida familiar, comum a todo homem, revelam a finitude em oposição à permanência. De todo modo, a visão do sujeito lírico é sempre mediada pela perda, restando apenas a beleza como possibilidade de perfeição e, talvez, a arte como uma saída para a permanência desta beleza materializada. Assim como a princesa que encontrou a solução da imortalidade transformando-se numa enguia branca, o poeta afirma que "A criação é feita destas coisas que passam à minha / frente, como se um ecrã rotativo me fizesse descobrir tudo o que não tive/ tempo para fixar". ${ }^{24}$

Esta impossibilidade de fixar o momento e, portanto, paralisar a morte, também pode ser vista nas imagens constantes das estações do ano. Aleatoriamente outono, inverno, verão e primavera perpassam os poemas com a intenção de marcar a transitoriedade temporal: nada pára, tudo está em transformação, mas o poeta deixa entrever, em oposição à luz do verão e da primavera, uma recorrência maior dos tempos invernais: "pássaros do outono", 25 "o céu estava cinzento", ${ }^{26}$ "Isto era

${ }^{23}$ MARTELO, 2010, p. 146.

24 JÚDICE, 2012, p. 66.

25 JÚDICE, 2012, p. 12.

26 JÚDICE, 2012, p. 14. 
antes do inverno, quando os velhos começavam a morrer", 27 "a chuva que cai no outono também traz a melancolia que atravessa as almas", ${ }^{28}$ "e os pássaros/apanhariam os restos, com os seus bicos exangues / de um voo invernal". ${ }^{29} \mathrm{O}$ voo dos pássaros também está relacionado às estações reforçando a ideia de um ciclo natural em constante movimento. O livro, portanto, divide-se entre os retratos que tendem a fixar a beleza de um instante e o ritmo contínuo da vida.

\section{Sombreamentos}

É na esteira da repetição que o tom melancólico deste livro se formula de modo substancial. Independentemente da centralidade da oposição do preto e branco, amenizados pelas invasões de azul, dos pássaros e de tudo aquilo que se move, mesmo que imaginariamente a partir de um retrato, a existência humana começa a ser delineada através de um traço mais pesado e angustiante. Impressiona como a melancolia pontua esta obra de Nuno Júdice e conforma a subjetividade do sujeito lírico, de personagens, espaços e títulos dos poemas: "A melancolia de Orfeu", 30 "cantando a melancolia branda da/ província", 31 "e um resto de melancolia envolve/o gesto que amadurece o desejo", , "a melancolia de um fim de férias", 33 "e

\footnotetext{
${ }^{27}$ JÚDICE, 2012, p. 33.

${ }^{28}$ JÚDICE, 2012, p. 80.

${ }^{29}$ JÚDICE, 2012, p. 102.

${ }^{30}$ JÚDICE, 2012, p. 17.

${ }^{31}$ JÚDICE, 2012, p. 18.

32 JÚDICE, 2012, p. 26.

${ }_{33}^{3}$ JÚDICE, 2012, p. 32.
} 
os olhos tristes / condizendo com a melancolia da boca", 34 "conceitos que/se prendem à minha beira, uma melancolia de superfície,/a terra estéril da memória", 35 "Por entre imagens melancólicas, um brilho de sol", 36 "a chuva que cai no outono/ também traz a melancolia que atravessa as almas", 37 "e um rumor de/barcos encalhados na melancolia de viagens que nunca fiz", 38 "o grande navio da melancolia se afunda,",, 9 "Melancolia", 40 "'que obscuras melancolias irão alimentar a imaginação/de quem der as moedas em troca do que parece ser nada?'" ${ }^{41}$

Me parece que a melancolia pode ser relacionada, diretamente, com a busca de um sentido para a condição trágica do homem: ser mortal.

... Mas o desconhecido aparece a cada passo; e quando a sombra invade o espaço onde tínhamos encontrado as respostas, e quando a noite do espírito esconde a luz que parecia possível, terá de ser outra a pergunta. "De onde vem este ser?"

(...)

\footnotetext{
34 JÚDICE, 2012, p. 36.

35 JÚDICE, 2012, p. 45.

36 JÚDICE, 2012, p. 57.

37 JÚDICE, 2012, p. 37.

38 JÚDICE, 2012, p. 81.

39 JÚDICE, 2012, p. 82.

40 JÚDICE, 2012, p. 92.

${ }^{41}$ JÚDICE, 2012, p. 97.
} 
... é uma angústia que

atravessa a consciência que nos empurra

para a treva onde os deuses celebram

o sacrifício do fim ${ }^{42}$

De um modo mais irônico, o sujeito lírico busca uma estratégia para escapar da "sensação de que o tempo corre contra nós" 43 como mostra o poema "Às vezes", em que a luta contra a morte (o fim) se aproxima de um ritual antropofágico falhado:

Às vezes sentimos que o tempo chegou ao fim, que as portas se estão a fechar por trás de nós, que já nenhum ruído

de passos nos segue; $\ldots$

(...)

A solução é pegar

no fim e metê-lo à boca, como se fosse uma pastilha elástica, derreter o sabor que o envolve, por amargo que seja, e no fim pegar nesse resto que ficou e, tal como se faz a pastilha elástica, deitá-lo fora. Para que queremos nós o nosso próprio fim? Já bastou tê-lo saboreado, derretido na boca, sentido o seu amargo sabor. ${ }^{44}$

Inversamente às pastilhas elásticas que são doces e endurecem quando perdem o sabor, por isso são jogadas no lixo, "o fim", ainda que seja mastigado, triturado, esmagado e derretido, deixa o seu amargor colado à língua. Imageticamente, esta mastigação, este movimento de ir e vir dos lábios simula também uma ruminação infinita sobre a

${ }^{42}$ JÚDICE, 2012, p. 22.

${ }^{43}$ FREUD, 2011, p. 85.

44 JÚDICE, 2012, p. 55. 
morte, este pensamento indigesto, espécie de fala contínua que não alcança nunca a compreensão. O esquecimento da morte, ou seja, de que a vida nos será tirada, é, portanto, apenas temporário, pois fica sempre um resto de fel lembrando a todo o tempo a condição trágica do homem, reforçando que a negação da morte como algo natural e inevitável mergulha o homem numa melancolia ainda mais profunda. Como aponta Freud em Luto e melancolia:

O investimento de objeto provou ser pouco resistente, foi suspenso, mas a libido livre não se deslocou para um outro objeto, e sim se retirou para o ego. Lá, contudo, ela não encontrou um uso qualquer, mas serviu para produzir uma identificação do ego com o objeto abandonado. Desse modo, a sombra do objeto caiu sobre o ego, que então pôde ser julgado por uma determinada instância como um objeto, como o objeto abandonado. ${ }^{45}$

Outras gradações de sombras construindo o percurso humano desenhado por Nuno Júdice. Há ausência de deus ou de deuses que possam assegurar ao homem alguma possibilidade de completude ou de explicação para a existência, descartada como podemos ver no poema "Te Deum" cuja configuração nos remete a um deus "alquebrado" de "olhos cegos" e "asas envelhecidas", ou prosaicamente em "Nova Suma Teológica" em que a invisibilidade (inexistência?) de deus, oculto nas nuvens, pode ser explicada através do café que existe por baixo da espuma, ou ainda um "deus obscuro" que "não consegue/ sair de dentro do cipreste, a não ser que o cortem/ e que a sua madeira, depois de seca, seja queimada/na lareira do inverno..". ${ }^{46}$ Também a crueldade entre os homens, especialmente o

45 FREUD, 2011,p.61.

${ }^{46}$ JÚDICE, 2012, p. 34. 
sofrimento daqueles que são esmagados pelo poder social, é trazida para os poemas por um viés essencialmente realista em que as diferenças de classe e os preconceitos são claramente reconhecíveis. Da pobreza, "Os pobres ficavam à porta à espera que/lhes levassem a comida./Olhavam para dentro da casa, às escondidas,/e viam as paredes de mármore, o chão de azulejos, as escadarias/de pedra, as portas de grandes salões onde nunca iriam/entrar.", 47 ao apagamento do outro, "Lembro-me dela na cozinha,/sentada, em silêncio, como se fosse um objecto", ${ }^{48}$ culminando com a radicalidade do poema "Arbeit Macht Frei", cuja memória dos campos de concentração nos alerta sobre o modo como os "bons profissionais", a funcionalidade dos sistemas e o desenvolvimento da economia podem por a humanidade novamente em risco:

Punham o comboio em marcha quando a hora chegava. Carruagens fechadas, vagões atrelados, o caminho era em frente. Olhavam a paisagem, quando se distraíam; mas logo voltavam a atenção para os carris, gracejando ao trocarem de lugar quando chegava a hora das refeições. Nas paragens, bebiam pela garrafa; e nem davam pelo que se passava atrás deles: estava longe o destino, as paragens eram muitas, e tinham de as compensar com horas extraordinárias para cumprir o horário: regulamentos são ordens, estavam à sua espera, e só depois de feita a entrega podiam mudar o sentido da máquina e fazer o caminho de volta, vagões vazios e limpos, e tudo a andar mais depressa porque já não havia peso a atrasar a marcha. São assim os bons profissionais, cumpridores,

47 JÚDICE, 2012, p. 35.

48 JÚDICE, 2012, p. 36. 
e não há notícia de greves, desvios, perguntas sobre o que enchia os vagões. ${ }^{49}$

\section{As formas e o fundo}

É preciso lembrar que Nuno Júdice, além de poeta, é ficcionista, ensaísta e crítico literário e que, muitas vezes, pratica em sua obra uma mistura de gêneros. A poesia lírica, de modo especial, pressupõe uma integração com a prosa, sem perder a qualidade da subjetividade essencial à primeira.

Diria, de modo enfático, que independentemente do caráter meditativo constitutivo de sua poesia que reforça o papel do mundo exterior na construção da subjetividade do sujeito lírico, Fórmulas de uma luz inexplicável se aproxima da épica, não só do ponto de vista formal, mas também na intenção de narrar poeticamente um acontecimento.

É possível entrever nestes mais de oitenta poemas o esboço de uma construção épica através de alguns títulos que sobressaem no conjunto: "Projecto" (poema de abertura), "Invocação" (segundo poema), "Dedicatória" (décimo quinto) e "Epílogo" (encerra o volume). A preferência pelo título "Projecto", em oposição à proposição, alude a uma escolha que quer se construir no futuro, mas que já, de saída, aponta para o fracasso: "procuro a terra branca de um outro/continente, os montes áridos de um litoral/tempestuoso, o fundo secreto de uns olhos/abertos para o coral da eternidade. Perdi-me/nessa procura;". ${ }^{50} \mathrm{O}$ sujeito lírico em sua procura não apenas se perde, mas também se torna "cego" diante da partida dos

49 JÚDICE, 2012, p. 70.

${ }^{50}$ JÚDICE, 2012, p. 11. 
barcos saídos de um porto imaginado, da felicidade desfeita, "nos olhos/vazios dos afogados". O tema do fracasso, ou do sonho fracassado (e por que não da viagem fracassada?), é retomado também em "Invocação", a partir da imagem do canto dos pássaros vinculado ao ciclo da natureza. Seu processo de migração alude à temporalidade do homem e, talvez, aqui já se possa perceber os traços que vão delineando o embate do homem com a morte - "que sabem os pássaros do outono que chega,/com seu fundo de nuvens, derramando o cinzento/ sobre o céu da memória?", 51 "Quantas vezes me avisaram, esses pássaros, do/que estava para vir" ${ }^{52}-\mathrm{e}$, ao mesmo tempo, a força da poesia como possibilidade de apaziguamento e sentido para a existência - "Mas é no presente que o seu canto me/toca;e dou-lhes, no abrigo da estrofe,/um ninho de palavras onde o seu sono se/recolha do inverno, e os seus olhos fechados/guardem a imagem do azul, o desejo do voo, e/um restolhar de folhas no vento da tarde."53

A presença de personagens como Édipo, Orfeu, Enéas, de autores como Oscar Wilde, Unamuno, Pessoa, Paul Celan, de artistas da dimensão de Millet, Camille Claudel misturados a um sujeito lírico que essencialmente vê com seus olhos ou colado aos olhos de outros, as situações poeticamente criadas, tudo leva a pensar, em alguma medida, no sentido da existência. Diante deste tema, o poeta busca áreas de respiro no azul, na beleza, no resgate de alguma subjetividade desvinculada da lógica de mercado como mostram os poemas "Canto do penhorista" e "Feira de velharias", busca vã, pois, ironicamente, nos avisa que, independente das possíveis saídas, a sutil

51 JÚDICE, 2012, p. 12.

52 JÚDICE, 2012, p. 12.

53 JÚDICE, 2012, p. 12. 
diferença etimológica entre o "plano" e o "projeto" acaba por nos colocar a pergunta fundamental: "se o destino dos mortos faz parte de algum plano,/ou se o projeto de viver se fecha com a morte." ${ }^{54}$

Fadados ao fim, forma finita, o fundo que sustenta esta trajetória épica - em tom menor, cujo homem alquebrado, feito de carne e osso, resiste melancolicamente a sua própria falta graças à navegação da mulher e do poema. "Epílogo" consegue unir as duas forças que organizam este livro: a morte e o amor. "O inverno é esta mancha que alastra pela página, /.../Mas afasto-me dele, e entro na casa onde/me esperas.../E o inverno fica do outro lado da porta." ${ }^{55}$

Neste livro, o esquema épico pode até prescindir da sua quarta parte - a narrativa histórica - mas não abre mão da narrativa da subjetividade do alquebrado herói lírico, cujas rotas aportam no poema "Dedicatória", onde reencontra um "tu" carregado de afetividade: "Para ti, de corpo aberto... é o poema que os deuses/esqueceram numa antiga encruzilhada." 56 A presença da mulher amada é capaz de restituir ao homem a sua paz: "Então ouço-te rir. E esqueço-me das variações/do tempo e da alma, como se o teu riso apagasse/dúvidas ou interrogações..." ${ }^{57}$

Em Fórmulas de uma luz inexplicável não existem, aparentemente, grandes acontecimentos, enfrentamento de mouros ou lestrigões, concílio de deuses, descobertas de novos orientes, e, sim, um poeta-pintor que tudo vê, olha e registra do seu pequeno mundo sem deuses. Ver (ver e seus verbos

\footnotetext{
${ }^{54}$ JÚDICE, 2012, p. 12.

${ }^{55}$ JÚDICE, 2012, p. 108.

${ }^{56}$ JÚDICE, 2012, p. 26.

${ }^{57}$ JÚDICE, 2012, p. 28.
} 
sinonímicos são uma constante nesta obra, assim como, de modo especial, o canto X dos Lusíadas) é o seu modo de resgatar o já vivido e recuperar o cotidiano do homem, radiografado em preto e branco, deixando entrever as miudezas da vida e o embate entre a memória e o presente. Sem recusar as fórmulas e o inexplicável, a luz deste livro pertence ao século XXI.

\section{Bibliografia}

Coelho, Eduardo Prado. A poesia ensina a cair. Lisboa: Imprensa Nacional/Casa da Moeda, 2010.

Freud, Sigmund. Luto e melancolia. Tradução, introdução e notas Marilene Carone. São Paulo: Cosac Naify, 2011.

Martelo, Rosa Maria. A forma informe: leituras de poesia. Lisboa: Assírio \& Alvim, 2010.

\section{Resumo}

Este texto propõe pensar o livro Fórmulas de uma luz inexplicável,l de Nuno Júdice, como uma pequena epopeia do homem contemporâneo, feita de falhas e rasuras, em constante diálogo com as artes visuais.

\section{Resumé}

Ce texte propose penser le livre Fórmulas de uma luz inexplicável, de Nuno Júdice, comme une petite épopée de l'homme contemporain, faite de failles et de ratures, dans un dialogue constant avec les arts visuelles. 